\title{
Visual Interventions: The Power of the Pen for Effective Communication
}

\author{
Stefan Gross \\ Neuland \& Partner, Development and Training, Fulda, Germany
}

\begin{abstract}
Pictures, words, and patterns are the major tools of visual facilitation. Ever since, these powerful tools have been used live in discussions to support brainstorming, decision-making or teaching and learning processes. However, their utilization as a powerful instrument today is lacking of a theory that helps to understand conditions, possibilities and effects of visual interventions for effective communication. This article is a first step towards this direction by introducing the concept of four areas focusing craftsmanship, the corresponding intellectual process, the filter-effects and the impact on participants' communication.
\end{abstract}

Keywords: Visualization; facilitation; communication; group dynamics; workshop; meeting; culture; human resource management; skills development; teachingmethods; learning process

"Power corresponds to the human ability not just to act but to act in concert. Power is never the property of an individual;

it belongs to a group and remains in existence only as long as the group keeps together."

Hannah Arendt - Power and Violence

Ever since, live-visualization has been a part of the basic tool-box anybody is using while working in and with groups. In school-days, the media is the blackboard coming along with a clear definition of the roles: The teacher is the one in front who writes while students have to copy it and are on cleaning-duty afterwards. Later, in the 1970s, the dusty chalk was replaced by the modern flipchart or whiteboard together with fancy boardmarkers in the business world. Still the modus has remained the same: One is writing and the others are more or less passively watching. A new way of visualization was then introduced with the arrival of pin-boards and cards. Now, the facilitator was no longer responsible for the content but guided the process and structured the discussion within the 
70 S. Gross

group. Not accidently, this paradigm-shift took place at the same time when team-work became the modern way of working in the production sector (Goeudevert, 1995).

Since the 1990s, digital devices have conquered our life-world and meeting-rooms and are standard equipment nowadays - and we are as used to them as to the blackboard during those days in our classroom. Surprisingly the good old flipchart still survived which might be astonishing as not everywhere where you can find one, you will find a filled-up marker, too. And not at every place where you have markers, you find blank paper. And even in case you find both - paper and functioning markers - facilitators and participants are often surprisingly reserved in using them. In expeditions through today's meeting-rooms you can find at least two stereo-types of charts. The first one is close to art, the colorful result of a sophisticated and time-consuming handicraft process in advance of the workshop. The second one, which you find even more often, is a cryptic sketch, not understandable for any observer from outside and even for the artist himself hardly to understand ex post. If the space for interpretation is as open as in the latter, visualization will not contribute to the communication process effectively. And, if it needs a lot of time and talent, as described in the first case, it will be impossible to translate it into action spontaneously in order to react on the present dynamic of the discussion.

\section{The Four Areas: Craftwork - Brainwork - Filterwork - Powerwork}

To use the powerful effects of flipcharts during meetings is not as difficult as it may sound. Follow some basic recommendations and you will achieve a maximum of output with a minimum of investment. Those, who do neat and clean work with the chart underline their professionalism and send appreciative signals towards their participants: Look! Your active participation is precious, that's why I put your words on the chart and write visibly. From this perspective, the challenge of using a flipchart in a professional way is mainly a question of craftsmanship. Clear and easy are therefore key-indicators for a pragmatic realization in live situations.

Once you know, how to make best use of the visualization tools, the question regarding the content occurs: Which contribution among the flood of spoken words is worth to be visualized? Do we need more details or a guiding structure at the moment? Should I write in words or use the powerful effects of pictures? All these questions have to be answered within seconds! Craftwork and brainwork go hand in hand (Agerbeck, 2012; Roam, 2008).

In addition, you have to be clear on the objective of your visual interventions: Firstly, you have to decide and question yourself: Do I want to interfere in the communication process or is it just for a parallel documentation? In case you will interfere: Which effect do I intend, where do I want to focus attention onto? Do I use the power of the pen to emphasize my own position to mark out the discussion or to clarify something vaguely? Do I want to accelerate or reduce the speed of discussion? This filter-power is not only an essential help for the facilitator but also serves the discussing group by providing 
orientation and different opportunities to continue the debate. With the help of constant visualization you dissolve misunderstandings, support good decisions and achieve a high commitment of all participants.

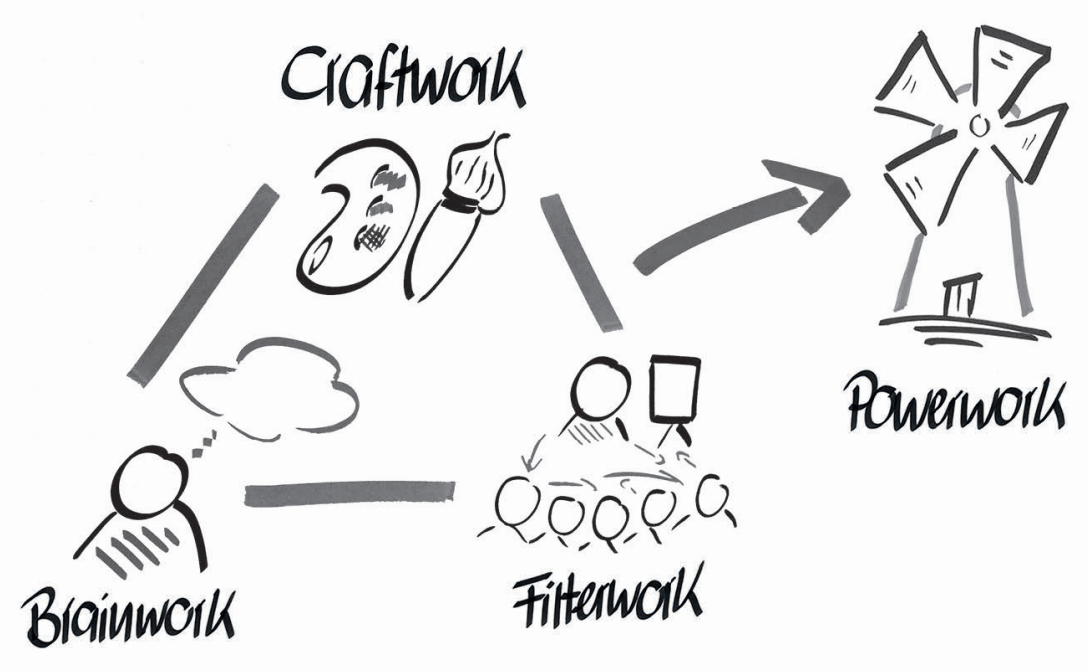

Figure 1. The four areas.

In this way, visualization becomes more than just an additional and unnecessary illustration. It provides a powerful set of various tools to structure content, to control the discussion and to reduce complexity. As a visual facilitator, you enable a group to work focused on subject matters, solve conflicts and achieve results! Only if all areas, the methodical craftwork, the reflective brainwork, and the interactive filterwork are harmonizing in concert, the power of visualization can be actualized in meetings and workshops to make a real difference. While actively, constantly and consciously interfering in the communication-process, the qualities of co-creative work change, too. Artificial discussions and the competition for attention are reduced to a minimum. The participants experience self-efficacy and respect towards every opinion and contribution. Therefore visual interventions have not only impact on the factual level but are simultaneously an important part of relationship building.

\section{Craftwork}

According to Richard Sennett, real craftsmanship, as an expression of skills, can be identified concerning three indicators: The engagement for one's issue, a distinct ability to judge quality and a consequent interrelation between hand and head: "Every good craftsman conducts a dialogue between concrete practices and thinking; this dialogue evolves into sustaining habits, and these habits establish a rhythm between problem solving and problem finding." (Sennett, 2008, p. 9). 
72 S. Gross

In our everyday-life, the distinction-line between hand and head, theory and practice, problem and solution or craftsman and artist seems quite universal, being the result of a socio-cultural process of demarcation over centuries. But it is losing its clarity at that point, where the interrelation shifts to the main focus. To become a real champion in craftsmanship means to be innovative seeing the same old things with new eyes from a new perspective, to optimize your own doing via repetitive learning and practicing, to question yourself permanently becoming able for self-criticism and develop a "fluid join between problem solving and problem finding" (Sennett, 2008, p. 33) - these are abilities that are not only the result of a mechanical process but require reflected doing. "You think and you do at the same time" (Sennett, 2008, p. 40).

Someone who understands his craftsmanship could be recognized not only during the process of making but also from the results, the products, the object standing at the end of the creative process. In our case, these are the charts which summarize the major aspects of a conversation and enable any participant or observer to re-construct the presented ideas in an easy, focused and systematical way. The achievement of the visual facilitator is to transform spoken words in real time into text and pictures. The usability for further communication is therefore the quality indicator of the visualization. From the perspective of craftsmanship only, clarity and good visibility are the main indicators. Healthy pragmatism is preferred in comparison to artistic expression as the latter might become an end in itself and is misleading from the important aspects (Mayer, 2008, p. 24).

For professional visualization three elements are very basic. At first, it is a clear and visible handwriting. This has less to do with talent but the more with focused attention and awareness - not only of the content but at the same time of the doing! Filled-up markers to focus your writing on the body of lowercase letters (instead of ascenders and descenders) in a simple style and closely written together - more knowledge of calligraphy is not necessary (Neuland, 1998)! The rest is practice and self-discipline.

Second, basic knowledge in composition of charts is of help to produce a clear impression of the whole - even in case the structure itself is developed live during the process. It is recommended to use colors, shapes and structures in a standardized way and to keep the final picture already in mind while drawing the first line. Which shape do I use best for which purpose? How much content do I expect to come? Where do I probably need further space? Is the chart going to be developed from top to down, from the center to the outline or do I place a structure first and fill in the blanks afterwards? React as soon as changing is needed and keep the final picture always in mind. It is just as simple as learning to draw for children: Use simple geometric basics, color to highlight and combine text and pictures. Less is more in the visualization context! Once you start you will easily create your own basics to be used in different contexts. Finally, take care that it suits to the conversation and the participants. 


\section{Brainwork}

As soon as you have routine in handling the visual tools and craftwork practically you can concentrate on the parallel brainwork. To reflect the effects of visual interventions in the communication process, the following dimensions are influencing:

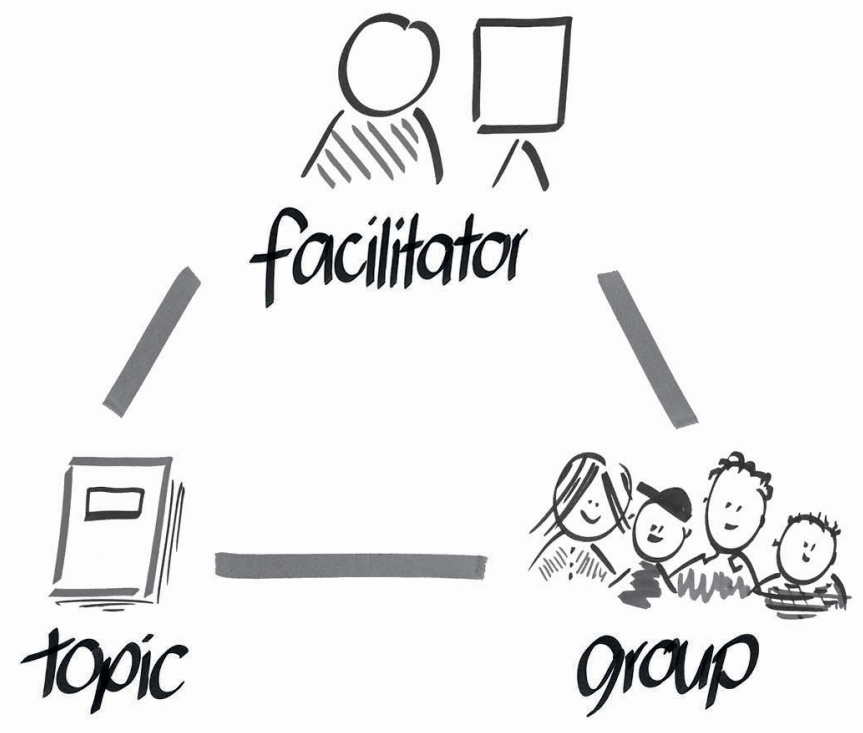

Figure 2. The process dimensions.

- The topic of the communication and the level of understanding

- The role of the visual facilitator for structure, coordination and documentation

- The group of participants in the process

Understanding the topic and its basic structure, detecting patterns and developing categories is the fundamental work in advance and parallel to the realization on paper. Dan Roam is describing it as a correlation of "Look" and "See" (Roam, 2008, p. 35). While "Look" is focusing on the perception of the outside world, "See" is describing the internal process of how one recognizes, organizes and filters information. In a constant process of circulation, perceptions and contents of the conversation are compressed until a first "Image" arises, which is drawn finally ("Show"). The ultimate professional visualization will only be possible if you already know what you want to show. Brainwork is guiding your craftwork. Anticipating the effects of your visualizations for the ongoing communication is determining the choice of suitable visual tools.

Being a visual facilitator you must have a clear idea in which way your intervening tools (text, pictures, patterns) influence the other participants' communication. Writing text leads to clarity, is unambiguous and evokes high identification in case you write exactly the words of others. Last but not least, it forces everybody to phrase his idea precisely as it is 
74 S. Gross

taken literally. "How can I write it down for you?" is a key-question for every facilitator. The more in cases of making decisions or dissolving misunderstandings text and words are basic helpers in any meeting.

To intervene with pictures like pictograms or simple graphics means to open the ground for multiple interpretations or associations and to document heterogeneity and plurality without restriction. Doing this helps to take many people along with you and include various perspectives. Pictures do often cause a spontaneous plausibility, are easily understood, lead to consensus and help to get access to implicit and explicit knowledge because of their vague determined nature (Schmeer, 2006, p. 125). Even contradictions can be expressed without neglecting the differences in false simplification. With a picture one can document various elements showing their complexity at the same time without shortening important aspects too fast or too early.

"Leadership" as one example can be illustrated by a horse with tight or loose reins, "motivation" can be discussed with carrots or whips, and the question "Who does really lead?" could be answered by discussing the two options: the horse or the horse-man? To debate on the leadership topic in that way initiates a process of perspective-taking avoiding answers of social conformity and is going much deeper. If the group is ready, the dialogue takes a new course, new analogies arise and new distinctions are drawn. Simply draw the head of a horse with a few lines and the discussion may start. With questions you can now lead the group to obtain a re-translation to their own personal leadership-context enriched with new insights and previously unrecognized aspects (Mahlmann, 2010).

Patterns, as the third option for visual interventions, are a useful tool to structure and organize the debate. Here, the reduction of complexity is the objective to enable a group to discuss a topic systematically without losing the big picture. Especially in complex groupsettings it is advisable to make up our minds in advance regarding patterns, schemata or categories which could be used later or directly on the spot during the debate helping every participant to stay on track. What are basic positions or elements of the discussion? Which categories go well with the topic? Are there any connections to previous debates? Where is it helpful to look in common aspects, where is a clear differentiation the right choice? As an intervening tool on the meta-level patterns provide clarity in situations where otherwise the discussion would just circulate or lead to dead ends. Along a clearly visualized guide-line the talk can take place in a focused and deepening way. Mainly in situations where different options have to be compared with each other a transparent matrix with clear categories helps to make good decisions (Lowy \& Hood, 2004).

Should I visualize or not? The answer to this question has much influence on our third dimension - the group or the stakeholder in your discussion. Live-visualization in the arena during a conversation decelerates and focuses on the visualized contents. To discuss along a differentiated pattern avoids redundancy and one-sided argumentations. The facilitator can easily guide the communication process and mark open issues without becoming the 
master-teacher overwhelming others. The pattern could be part of the introduction after a coffee-break or on the spot; at any time where more structure is needed to erase confusion and to restructure the process. By doing this visual interventions are a key-tool to control dynamic and to focus on the content level with objective distance for every speaker (Mayer, 2008, Schmeer, 2006). Did I really tell these words? What does this exactly mean? Isn't an important part missing? Seeing it written, I have to think twice... These precious moments of realization and illustration have clarifying effects and support the facilitator to control the group-dynamics even in challenging and emotional situations. A simple pen becomes a neutralizer, a whip or an enlightening torch directing towards the solution.

These basic tools of live-visualization, text, pictures and patterns and their effects can be used in various contexts and in different stages of a conversation. Intuitive fast thinking is playing a key-role becoming a master in this field. Daniel Kahneman is describing thisintuition of experts as anability where you "have learned to recognize familiar elements in a new situation and to act in a manner that is appropriate to it" (Kahneman, 2011, p. 12). Besides craftsmanship, experience and knowledge as the brainwork is therefore a keyindicator of the visual master.

\section{Filterwork}

If you want to purify, you need a filter. This is similarly true for fresh water treatment plants with their mechanical, chemical or biological treatment procedures as for the work in a communication process. The major challenge is to choose the right sieve to distinguish important and valuable ingredients from non-important bypass aspects in the never-ending flow of information. It has become successful practice in these cases to turn around ideas and aspects as long as necessary until and unless quality separates from the rest in a critical discourse - for visual facilitators sometimes even possible by drawing simply on the back of a napkin (Roam, 2008). On its way from the dialogue to the paper, sometimes the shape changes and becomes even clearer than only in words. Sennett describes this phenomenon as a "man-made metamorphosis" (Sennett, 2008, p. 126). With visual help rough phrases turn into distinct structured statements, wooly thoughts are decoded and appear transparent and understandable. The liquid raw-material of spoken words changes its state by becoming solid and ready for further processing. Nonetheless, the original quality of the primary source is of vital importance to create good products in the end.

How visualization can unfold its aid for the communication process depends extremely on the objective the communication partners do have and in which way it is integrated as a constitutive part of the discussion. Mainly in situations where the why-should-we-dothis-question is still open, where the sequel of the points is under discussion or different perspectives are not clear, a visual focus is of great help for everybody to orient himself. Providing this clue you cannot only collect people from where they actually stand, but you can also guide them to a place they would not reach without your visual assistance. 
| 16 S. Gross

To do the treatment-work for others does not mean that you have to do this permanently solely and exclusively. It is most important to feed-back every step to the other partnersconsequently. You may guess which topic is at the moment most important for everybody and what actual needs others might have, but you can never be $100 \%$ sure. Therefore it is recommended to put several filters and treatment-steps into sequel and to combine them virtuously. Picture by picture, pattern by pattern, chart by chart the communication-flow is bypassed, sometimes more open, sometimes closer along these visual guidelines up to the desired end.

In some cases you can only recognize the value of your visualizations after the communication has taken place. As an example, in coaching settings itnormally starts with the first incidental sketches to orient yourself and the client in the field of conflict. The basic objective is to understand the structure of involved people and their relations to get a first overview. In this process it may happen that these drawings are not only of great help for the coach, but the client himself experiences an act of self-dissociation. Together you watch on the overburdening constellationfrom outside. This distanced view may already lead to new insights regarding causes and solutions (Mayer, 2008). The visual clarification is a key-tool to regain your capacity to act in complex and confusing situations.

In larger groups these visual interventions only work if they are understood and accepted by everybody, which makes the situation more challenging. Seldom, the first draft is the best. So you have no other choice but open the discussion for mutual exchange until and unless everybody can give his commitment. This requires courage, even in nebulous situations to start from anywhere in order to create a first fixed point. On that score visualization is always trail action. The load capacity is always in abeyance and has to be checked regularly up to the point where it suits for everybody. To get into discussion on your visualizations and to modify them if necessary is no sign of incompetence but a seal of quality. The visual filterwork is regularly in danger to choose an inappropriate picture, to set the wrong focus or to ignore relevant facts. Anyhow, to make learning visible (Hattie, 2009), to invite for participation, to take different perspectives and roles, to check objectives with commitment from everybody and to show distinct areas for improvement in order to establish a failure- and feedback-friendly environment - these are the basic elements to make the key difference and promote the quality of any communication and learning process. Even a "wrong" visualization can have a strong impact - because as soon as the picture or the words are visible on the chart everybody has to behave towards it either by correcting it or in silent agreement. Wrong but strong - following this maxim will help you to clear out misunderstandings, to provide transparency and to help everybody to focus on the major points. In this way, even wrong ways lead to better orientation.

Doing the filterwork means to connect the basic elements in a unique way: the filter-function of the visual facilitator, the purifying and supplementing communicative treatment-work together with all participants and the structuring-process regarding the 
content. With the help of visualization it is quite easy to connect previous and present results in front of all involved parties. Let the visualized content become an integrated part of your conversation. Simply stick your charts on the wall, restructure your cards whenever necessary or find new headings if the old ones do not serve anymore. Links and shortcuts can be found, progress is visible and it becomes even clearer how much work and unclear points are still ahead of you and the group.

\section{Powerwork}

Live-visualization, as described with the help of these dimensions, has high potentiality to become a power-tool for any conversation. But this will only take place if you are aware of the effects of your visual interventions and a basic-skilled craftsman with the pen. It is more something like the regenerative power of a windmill than the one of a complex nuclear power plant. The power is strongest in case you set distinct and clear interventions utilizing the existing energy of the surrounding communication environment. Forces are combined and dynamic can rise which could be reverted to the communication process. An effectual circuit on various levels: you get clarity and commitment in a faster way, complexity becomes manageable, group-dynamics can be controlled and all participants feel appreciated and respected as they see their words visualized in a condensed version right in front on the chart. Besides the quality aspects on the content level, visual interventions create an essential surplus for the relation among all involved people. As the result of an engaged and proper debate, the topic itself becomes a lively and activating part of the dialogue leading to a deeper experience of self-efficiency of the group and its competence.

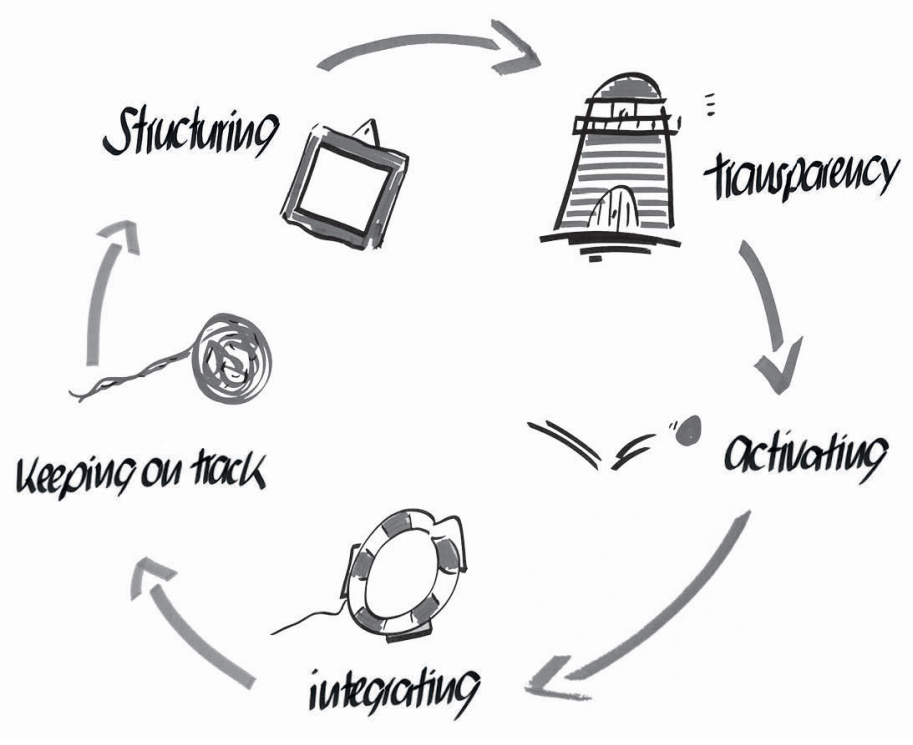

Figure 3. The five effects of visual interventions. 
78 S. Gross

Clear visual interventions help you regarding five dimensions: 1) providing transparency, 2) activating participants, 3) integrating standpoints and interests, 4) keeping everybody on track in the discussion and 5)structuring the guideline of the discussion. With the help of visual tools it should not be your intention just to produce show-effects or useless decoration. As a part of your ongoing reflection of the communication process, these interventions aim to raise the quality of your conversation, either by giving initial ideas to start or by keeping the process alive. As everybody is interested in the topic and not at first in the form, the quality of your visualization will be judged mainly regarding its support towards the result.

Visual interventions are a powerful tool providing not only chances but contain even some risks to be aware of. In organizations, it is not always just about a cooperative relationship or the logically best result but sometimes a political game on opinions and interests. Meetings and workshops are therefore a great playground. Where these powerstruggles are dominant, visualization is always suspicious. If you are not interested in a common solution, you will hardly show motivation to follow a discussion-style which promotes exactly this. For those who want to influence in a discussion through various channels, any facilitator is a source of friction, who wants unnecessarily transparency and provides useless possibilities for active participation of all. If you are clever, as a lobbyist, you utilize exactly these powerful tools to bring your standpoint in front. The main reason for this is that visualization is highly infectious. Simply put a complex constellation in two textboxes, color them red and blue and everybody later one will speak about the "reds" and the "blues"; all other alternative options will be forgotten soon. You need a strong ability of distancing yourself not to follow that spontaneous plausibility and to keep your eyes open for alternatives. Especially regarding its suggestive and subconscious effects, the power of visual interventions can be experienced.

But visualization will only play a strong part in the conversation if it does not appear artificial, otherwise it will just be ignored. Still a lot of potential power is wasted in workshops for two reasons: Either the visualization is prepared in advance, e.g. in power-point, but not utilized to structure the discussion or the documentation happens simultaneously in laptops or diaries without being part of the process itself. Only if your charts become a central part for all communication partners, if they are accepted and utilized, only then they can realize their potential and help to structure, to focus, to mirror, to allow comparisons and to provide clarity to all. Even in difficult and challenging situations it works to stay altogether on track towards an objective, to be more effective and efficient and to identify dead ends as well as bringing the communication back to the content level. All in all, quality rises not only regarding the results and solutions but also in view of a better communication culture and atmosphere. 


\section{Learning to Use Your Visual Tools}

If you cannot put the whole thing just on talent or experience, the question arises how to teach and learn the handling of visual tools. Every communication situation is unique and special. Anyhow, there exists a set of visual tools and recommendations that make the first steps quite easy. According to Richard Sennett as mentioned previously already, there exist three basic indicators for a mastership in any craftsman's approach: the fluid join between hand- and head-related work, a distinct understanding of quality and a passionate engagement towards your objective (Sennett, 2008). These factors are going to be now interrelated with our four areas.

The constant exchange between imagination and output, nearly simultaneously, requires that you should not have to concentrate on every single step anymore. Therefore you need practical experience and routine in handling the pen. The elaboration of standards of patterns and pictures for your own context is the backbone for the professional and fast implementation in live situations. Only if you do a professional handicraft job, your participants can focus on the visual offers and the direction of the process.

The parallel brainwork is guided by three aspects: My own perception and listening skills, the topic and its objective and the anticipation of the expectations and needs the other participants might have. More opening or closing of the topic? More structure or more flexibility? Looking behind the scenes and focusing complexity and context or do we need a first basic step to start at least somewhere? This way of thinking requires an orientation on structural aspects and a good feeling for the rhythm of conversations. Thanks to Dan Roam, who promotes in his "The Back of the Napkin" six basic questions that help you to focus through visualization on the very basic needs: "Who and What? How much? When? Where? How? Why?" (Roam, 2008, p. 15). For every question a simple drawing can be a helping friend to find the solution: Collecting ideas on cards (What do we have to do?), a bar diagram (How much time we need for each step?), a project structure (What are we going to do when?), an analytical pattern (Where is the cause for our problem?), a mindmap (How do the parts relate to each other?) or a decision-making-matrix (time vs. cost). Take care: It does not mean that you should answer all questions in one picture, but work step by step and interrelate them later on. A set of ideas helps to be able to find good visual interventions at the right time (Krogerus \& Tschäppeler, 2010).

Regarding your own aesthetic demands and the quality of your visualizations we recommend a healthy pragmatism in order to provide clarity and a goal-focus with speed instead of artistic virtuosity or the desire of completeness. The usability of your visual interventions is observable once they become an integrated part of the conversation - even if you are personally not satisfied with their appearance. While people are quite critical in case they find a spelling mistake or untidy line on any ready-made chart, once you work live on stage you can expect much more leniency. And, in case you are experienced and 
$80 \mid$ S. Gross

write even tidily on the spot, the fellowship of the group is guaranteed.

Therefore you need courage, presence, concentration, openness and spontaneity based on high confidence regarding the effectiveness of your visual interventions. No doubt, in case you leave the position of being just an average participant among others by standing up and going to the flipchart you expose yourself inevitably. And there are many good reasons on rainy days or in politically unfeasible situations to keep silent. In case you ask for the mandate from the group at the beginning, you declare your visualizations just as offers, you connect it to the present conversation and ask for additional comments or changing and eliminate possible objections, the probability raises tremendously that you will be successful in leading the group to a real consensus. Doing this visual facilitation is much more than just a short-term solution for critical situations; it is the beginning of a new communication culture within organizations.

\section{Note}

This article is a translated and modified version of: Gross, S. (2013). Visuelle interventionen. Über die machtvolle Wirkung von Live-Visualisierungen in Kommunikations prozessen. In T. Hake (Ed.), Von der Herausforderung, die Lösung (noch) nicht zu kennen. Entwicklungskonzepte für Organisationen und Menschen in Zeiten rapiden Wandels. Heidelberg: Carl Auer. By courtesy of Carl Auer Verlag, Heidelberg, Germany.

\section{References}

Agerbeck, B. (2012). The graphic facilitator's guide. How to use your listening, thinking \&drawing skills to make meaning. Loosetooth.com Library.

Arendt, H. (1970). Macht und Gewalt. München, Germany: Pieper.

Goeudevert, D. (1995). Mündigkeit. Ein Gespräch mit Andreas Gruschka. Wetzlar, Germany: Büchseder Pandorra.

Hattie, J. (2009). Visible learning: A synthesis of over 800 meta-analyses relating toachievement. London, England and New York, NY: Routledge.

Kahneman, D. (2011). Thinking, fast and slow. London, England: Penguin Group.

Krogerus, M., \& Tschäppeler, R. (2010). The decision book. Fifty models for strategic thinking (J. Piening, Trans.). London, England: Profile Books.

Lowy, A., \& Hood, P. (2004). The power of the 2x2 matrix: Using $2 x 2$ thinking to solve business problems and make better decisions. San Francisco, CA: Wiley Imprint.

Mahlmann, R. (2010). Sprachbilder, Metaphern \& Co.: Einsatz von bildlicher Sprache in Coaching, Beratung und Training. Weinheim and Basel, Germany: Beltz.

Mayer, C. (2008). Hieroglyphen der Psyche. Mit Patientenskizzen zum Kern der Psychodynamik. Stuttgart, Germany and New York, NY: Schattauer.

Neuland, M. (1998). The world of moderation. The Neuland approach: Philosophy and techniques for extraordinary group performance and active learning. Eichenzell, Germany: Author. 
Roam, D. (2008). The back of the napkin. Solving problems and selling ideas with pictures. London, England: Penguin.

Sennett, R. (2008). The craftsman. London, England: Penguin Group.

Schmeer, G. (2006). Die Resonanzbildmethode - visuelles Lernen in der Gruppe.

Selbsterfahrung - Team - Organisation. Stuttgart, Germany: Klett-Cotta.

Sibbet, D. (2010). Visual meetings. How graphics, sticky notes \& idea mapping can transform group productivity. New Jersey, NJ: The Grove. 